\title{
PERCEPÇÃO DOS PROFISSIONAIS DE ENFERMAGEM SOBRE O SEU CONSELHO DE CLASSE
}

Wellyson Souza ${ }^{1}$ Ianne Mayara² Andeson Mayk ${ }^{2}$ Thalys Maynnard ${ }^{2}$ Gerson Silva ${ }^{3}$ Adriana Lira ${ }^{4}$ http://orcid.org/0000-0002-3977-2556 http://orcid.org/0000-0002-6824-8833 https://orcid.org/0000-0001-7398-6630 http://orcid.org/0000-0001-8758-6937 http://orcid.org/0000-0003-2645-8020 https://orcid.org/0000-0002-3236-4605

Objetivo: analisar a percepção dos profissionais de enfermagem acerca do papel do seu conselho de classe como órgão fiscalizador do exercício profissional. Método: pesquisa exploratória, descritiva, com abordagem quantitativa, desenvolvida em um hospital universitário, da rede privada de saúde, na cidade de João Pessoa, Paraíba. A coleta de dados foi realizada com todos os profissionais de enfermagem que exercem suas atividades laborativas no hospital, perfazendo uma amostra de 15 entrevistados. Resultados: distribuídos em duas variáveis denominadas "papel do conselho de classe" e "responsabilidades e deveres para com a profissão", onde 73\% dos profissionais reconhecem o conselho como órgão fiscalizador. Conclusão: constata-se que os profissionais de enfermagem reconhecem o verdadeiro papel do seu conselho fiscalizador, porém ainda atribuem, por vezes, as funções que deveriam ser exercidas pelos sindicatos da categoria ao COREN.

Descritores: Enfermagem; Profissionais de enfermagem; Ética profissional.

\section{PERCEPTION OF NURSING PROFESSIONALS ABOUT THEIR COUNCIL}

Objective: to analyze the perception of nursing professionals about the role of their class council as a monitoring body for professional practice. Method: exploratory, descriptive study, with quantitative approach, developed in a university hospital, private health network, in the city of João Pessoa, Paraiba, Brasil. The sample consisted of 15 nursing professionals. Results: distributed in two variables called "the role of the class council" and "responsibilities and duties to the profession", where 73\% of professionals recognize the council as a supervisory body. Conclusion: it can be seen that nursing professionals recognize the true role of their supervisory board, but sometimes they also assign the functions that should be performed by unions of the category to Nursing Regional Council.

Descriptors: Nursing; Nursing professionals; Professional ethics.

\section{PERCEPCIÓN DE PROFESIONALES DE ENFERMERÍA SOBRE SU CONSEJO DE CLASE}

Objetivo: analizar la percepción de los profesionales de enfermería acerca del papel de su consejo de clase como órgano fiscalizador del ejercicio profesional. Método: investigación exploratoria, descriptiva, con abordaje cuantitativo, desarrollada en un hospital universitario, de la red privada de salud, en la ciudad de João Pessoa, Paraíba. La muestra fue compuesta por 15 profesionales de enfermería. Resultados: distribuidos en dos variables denominadas "papel del consejo de clase" y "responsabilidades y deberes para la profesión", donde el 73\% de los profesionales reconocen el consejo como órgano fiscalizador. Conclusión: se constata que los profesionales de enfermería reconocen el verdadero papel de su consejo fiscalizador, pero todavía atribuyen a veces las funciones que deberían ser ejercidas por los sindicatos de la categoría al Consejo Regional de Enfermería.

Descriptores: Enfermería; Profesionales de enfermería; Ética profesional.

${ }^{1}$ Faculdade de Enfermagem Nova Esperança - FACENE. João Pessoa (PB)

${ }^{2}$ Centro Universitário de João Pessoa - UNIPÊ. João Pessoa (PB)

${ }^{3}$ Departamento de Enfermagem Clinica da Universidade Federal da Paraiba. João Pessoa (PB)

${ }_{4}^{4}$ Faculdade de Enfermagem Nova Esperança FACENE/PB. João Pessoa (PB)

Autor Correspondente: Wellyson Souza - Email: wellysonrep@hotmail.com 


\section{INTRODUÇÃO}

A enfermagem é definida como a arte e a ciência do cuidado integral e integrador em saúde, tanto no sentido de assistir e coordenar as práticas de cuidado, quanto no de promover e proteger a saúde dos indivíduos, famílias e comunidades ${ }^{(1)}$. É uma profissão que tem a possibilidade de operar, de forma criativa e autônoma, nos diferentes níveis de atenção à saúde, seja através de práticas assistenciais ou educativas, promovendo ou reabilitando os indivíduos( ${ }^{(2)}$.

A profissão de enfermagem nasceu a partir de um processo de evolução das práticas de saúde, onde se tinha como objetivo principal garantir ao homem a manutenção de sua sobrevivência ${ }^{(3)}$. No entanto, como atividade profissional institucionalizada, iniciou-se com a revolução industrial no século XVI e culminou com o surgimento da enfermagem moderna na Inglaterra, no século XIX(4).

No Brasil, a organização da enfermagem iniciou-se no período colonial, prosseguindo até o final do século XIX. Surgiu como uma simples prestação de cuidados aos doentes, realizada por um grupo formado, na sua maioria, por escravos que trabalhavam nos domicílios. Daí os cuidados também passaram a ser realizados nas casas de misericórdias, no ano de 1543, a exemplo da casa de misericórdia da Vila de Santos, Rio de Janeiro, Vitória, Olinda, Ilhéus, Porto Alegre e Curitiba ${ }^{(1)}$.

A regulamentação do exercício da enfermagem profissional no Brasil se deu através da lei n. 2.604, de 17 de setembro de 1955 , sendo criadas através desta as profissões de enfermeiro, obstetriz, auxiliar de enfermagem, parteira, enfermeiro prático ou prático de enfermagem e parteira prática. Em 12 de julho de 1973, através da lei n. 5.905, foram criados o Conselho Federal e Regionais de Enfermagem. Em 25 de junho de 1986, com a criação da lei n. 7.498, que derrogou a lei n. 2.604/55, a qual regulamentou definitivamente o exercício da enfermagem em todo o Brasil, tendo sido regulamentada através do decreto n. 94.406, datado de 08 de junho de $1987^{(5)}$.

Enquanto profissão componente da equipe de saúde, a criação do Sistema COFEN/COREN's foi muito importante no sentido de fiscalizar as ações dos profissionais de enfermagem, pois só assim essas atividades tendem a serem pautados em princípios éticos e legais, na perspectiva da proteção dos usuários do sistema de saúde nacional em todas as suas esferas administrativas.

A ética é a reflexão crítica sobre o comportamento humano que interpreta, discute e problematiza os valores, os princípios e as regras morais. A moral surge de um conjunto de valores criados pelos sujeitos em suas relações, distinguindo-se da ética que se constitui em uma reflexão crítica sobre a moralidade, a dimensão moral do comportamento do homem. Portanto a ética é percebida pelo indivíduo, envolve coerência, consciência e autonomia, enquanto que a moral a ele é imposta ${ }^{(6)}$.

A fiscalização do exercício profissional de todos que compõem a equipe de enfermagem deverá ser pautada em princípios éticos e legais, e é exercida pelos conselhos fiscalizadores, neste caso concreto, pelo Conselho Regional de Enfermagem fundamentado em determinações emanadas, principalmente do Conselho Federal de Enfermagem. Baseados nos princípios fundamentais do direito administrativo brasileiro e nos princípios éticos em vigor, a fiscalização tem a prerrogativa de educar as pessoas envolvidas e combater a atuação em desrespeito às leis, em favor do interesse público, direitos e liberdades individuais, contribuindo para a melhoria da qualidade dos serviços prestados à população(5).

A autorregulação no Conselho de Enfermagem se inicia com o registro e inscrição dos profissionais, como determina a Resolução COFEN n. 372/2010 e abrange todas as ações fiscalizatórias, incluindo as decisões, encaminhamentos administrativos e jurídicos decorrentes desse ato. É importante destacar que, o disciplinamento para o exercício legal das profissões que envolve a enfermagem brasileira, encontra-se inserido nas leis 2.604/55 e 7.498/86(5).

Diante do exposto, o presente estudo buscou responder ao seguinte questionamento: qual a real percepção que os profissionais de enfermagem têm acerca do seu consetho de classe? Portanto, objetivou-se analisar a percepção dos profissionais de enfermagem acerca do papel do seu conselho de classe como órgão fiscalizador do exercício profissional.

\section{MÉTODO}

Trata-se de uma pesquisa exploratória, descritiva, com abordagem quantitativa, desenvolvida em um hospital universitário, da rede privada de saúde, na cidade de João Pessoa, Paraíba. A população foi constituída por todos os profissionais de enfermagem que exercem suas atividades laborativas no hospital, perfazendo um total de 60 profissionais, distribuidos da seguinte forma: 15 enfermeiros e 45 técnicos de enfermagem. A amostra foi composta de forma não probabilística, por conveniência, estruturada em 15 destes profissionais, sendo cinco enfermeiros e 10 técnicos de enfermagem, que declinaram o interesse em participar voluntariamente da referida pesquisa. $\mathrm{O}$ estudo obedeceu aos seguintes critérios de inclusão: os profissionais que atuam há mais de um ano no serviço escolhido como cenário da pesquisa; estar presente no momento de 
coleta de dados; trabalharem com registro no conselho de forma ativa e regular; aceitaram participar do estudo de forma voluntária, assinando o Termo de Consentimento Livre e Esclarecido (TCLE); como exclusão: os profissionais que se encontravam em período de afastamento para gozo de férias e licença.

A coleta dos dados ocorreu por meio de um questionário, realizada no mês de setembro de 2017, após a aprovação do Comitê de Ética em Pesquisa (CEP) segundo CAEE: 75535517.3.0000.5179 e autorização expressa da direção do hospital elegido. Os dados coletados foram ordenados, organizados e posteriormente codificados e tabulados no programa Excel Office XP®, utilizando-se a estatística descritiva simples por meio das frequências simples e relativas, apresentadas em formas de tabelas; em seguida, os resultados foram discutidos à luz do referencial teórico da dinâmica do reconhecimento, da percepção do profissional com relação ao seu conselho de classe e as minuciosidades pertinentes à problemática do estudo.

Respeitou-se os aspectos éticos preconizados pela Resolução CNS 466/12, no art. III, que implica na preservação do participante da pesquisa em sua dignidade e autonomia, reconhecendo sua vulnerabilidade, assegurando sua vontade de contribuir e permanecer, ou não, na pesquisa, por intermédio do Termo de Consentimento Livre e Esclarecido, como também, a Resolução COFEN 564/2017, que trata do código de ética dos profissionais de Enfermagem.

\section{RESULTADOS}

Os resultados demonstraram-se satisfatórios perante análise, contribuindo para a construção sistemática da fundamentação das variáveis. Com relação aos dados sócio demográficos, verificou-se que $87 \%$ (13) dos pesquisados são do gênero feminino, enquanto que 13\% (02) pertencem ao gênero masculino, destes, 47\% (07) dos pesquisados estão inseridos na faixa etária entre 22 e 31 anos, enquanto que $40 \%$ (06) possuem idade entre 32 e 42 anos e apenas $13 \%$ (02) encontram-se com idade compreendida entre 43 e 50 anos. $87 \%$ (13) dos pesquisados não realizam outro curso na área, e apenas 13\% (02) referem ter concluido outro curso na área. Ressalta-se que, 40\% (06) dos investigados citaram que exerciam 40 horas semanais de jornada de trabalho, com igual percentual indicando 44 horas, enquanto que $6,6 \%$ (O1) citaram 60 horas, com igual percentual indicando 72 e 74 horas.

A análise dos dados permitiu emergir dois tópicos que foram correlacionados estatisticamente com cada variável presente no instrumento de coleta: 1) Papel do Conselho de Classe; 2) Responsabilidades e deveres para com a pro- fissão.

Quanto à análise da variável "Papel do conselho de classe", apresenta-se a tabela l, a qual demonstra em percentis a expressão dos profissionais de enfermagem sobre a função do seu respectivo conselho de classe.

Tabela 1 - Papel do conselho de classe, João Pessoa, 2017.

\begin{tabular}{|c|c|c|}
\hline Variáveis & $\mathbf{N}$ & $\%$ \\
\hline $\begin{array}{l}\text { Fiscalizar o exercício profissional da enfermagem (Enfer- } \\
\text { meiros, Técnicos e Auxiliares) }\end{array}$ & 11 & 73 \\
\hline Lutar por melhoria salarial & 07 & 47 \\
\hline $\begin{array}{l}\text { Promover eventos cientificos gratuitos para melhor capaci- } \\
\text { tar os profissionais inscritos }\end{array}$ & 06 & 40 \\
\hline Garantir a qualidade da assistência de enfermagem & 06 & 40 \\
\hline Oferecer serviços de saúde para os seus inscritos & 02 & 13 \\
\hline Fiscalizar os cursos de enfermagem (Nivel médio e superior) & $\mathrm{Ol}$ & 6,7 \\
\hline $\begin{array}{l}\text { Promover atividades de lazer para os profissionais de en- } \\
\text { fermagem }\end{array}$ & $\mathrm{Ol}$ & 6,7 \\
\hline
\end{tabular}

Na tabela 2, no que diz respeito à análise da variável "Responsabilidades e deveres para com a profissão", demonstrou-se em percentuais que, $73,0 \%$ (1l) dos profissionais afirmam ter que se manter atualizados ética e tecnicamente (participar de congressos, cursos, jornais e outros), bem como cumprir a legislação que disciplina a profissão de enfermagem (Leis do Exercício Profissional e Código de Ética). Já 53,0\% (08) demonstram ter que se manter em dia com suas obrigações financeiras no seu Conselho de Classe e votar nas eleições promovidas pelo Sistema Cofen/ Coren's.

Tabela 2 - Responsabilidades e deveres para com a profissão, João Pessoa, 2017.

\begin{tabular}{|c|c|c|}
\hline Variáveis & $N=15$ & $\%$ \\
\hline $\begin{array}{l}\text { Manter-se atualizados ético e tecnicamente (participar de } \\
\text { congressos, cursos, jornais e outros) }\end{array}$ & 11 & 73 \\
\hline $\begin{array}{l}\text { Cumprir a Legislação que disciplina a profissão de enfer- } \\
\text { magem (Leis do Exercício Profissional e Código de Ética) }\end{array}$ & 11 & 73 \\
\hline $\begin{array}{l}\text { Manter-se em dia com suas obrigações financeiras no seu } \\
\text { Conselho de Classe }\end{array}$ & 08 & 53 \\
\hline $\begin{array}{l}\text { Votar nas eleições promovidas pelo Sistema Cofen/Co- } \\
\text { ren's }\end{array}$ & 08 & 53 \\
\hline
\end{tabular}

\section{DISCUSSÃO}

O sexo feminino e seu papel na enfermagem demonstra a luta histórica de enfermeiras brasileiras pela institucionalização da profissão mostrando também a força que a mulher possui dentro da enfermagem; que as práticas cuidativas são vinculadas ainda ao gênero feminino, onde tais fatos ocorrem por associar a figura da mulher às práticas 
de cuidados do lar. Em alguns estudos mostra-se também que o gênero feminino ainda é o que predomina nas faculdades de enfermagem brasileiras, apesar da realidade estar mudando cada vez mais, onde homens estão se inserindo no meio científico da enfermagem, de uma forma geral ${ }^{(7)}$.

Os trabalhadores de enfermagem de maior idade provavelmente têm maior dificuldade de manter relações sociais satisfatórias em virtude das responsabilidades cumulativas ao longo da vida e pelo cansaço físico e mental do dia a dia. Assim, suas relações sociais passam a ser restritivas ao ambiente familiar. Em um estudo realizado ficou comprovado que a média de idade dos profissionais em enfermagem foi de 33 anos, o que os caracteriza como adultos jovens. Quanto maior a idade do profissional, pior sua qualidade de vida no domínio relações sociais e, quanto menor a idade do profissional, melhor sua qualidade de vida no domínio relações sociais ${ }^{(8)}$

A carga horária de trabalho semanal desenvolvida em um hospital público variou de 21 a 78 horas, sendo que a mediana foi de 42 horas. Enfatiza-se que a carga horária desenvolvida pelos sujeitos era de 36 horas/semana, para os contratados pela Fundação e, de 30 horas/semanais, para os funcionários públicos estaduais. Em relação ao retorno de férias, 71 (74,7\%), enfermeiros haviam retornado há mais de 30 dias, considerando-se a data de coleta de dados e 24 deles (25,3\%) há menos de 30 dias dessa data, o que justifica algumas respostas de carga horária semanal inferior a 30 horas $^{(9)}$.

Os profissionais de enfermagem têm uma carga horária exaustiva de trabalho, o que não proporciona condições de serem realizadas outras atividades na vida pessoal, em especial cursos de aperfeiçoamento(9)

Frente aos dados analisados, no tocante a carga horária semanal cumprida, pode-se afirmar que, alguns profissionais cumprem carga horária exaustiva na tentativa de suprir demandas laborais e, intrinsecamente, pessoais. A busca cotidiana que visa agregar a eficiência técnica e científica a uma postura ética que se respeita a singularidade das necessidades do usuário e do profissional, é vista e torna-se como desafio frente à realidade de horário semanal, especialmente na perspectiva de provocar inovações na produção de saúde, gestão e no cuidado(10).

Por vezes o profissional torna-se distante de seus familiares e de situações da vida diárias por ter jornadas de trabalho longas, tornando-se alienado, irritado e estressado. Deste modo, afasta-se do convívio social e familiar, direcionando a maior parte de seu tempo às atividades profissionais, deixando de lado questões subjetivas, pois passa a ver o trabalho em primeiro plano, sem perceber os prejuízos que está agregando não apenas para si, como também à família(11)

Os Conselhos Profissionais das diversas profissões têm a função precípua de realizar a fiscalização do exercício profissional em todo o território nacional, por delegação do estado brasileiro. Esta fiscalização não é exercida diretamente por ele, e sim através de órgãos que são vinculados ao poder público. Os conselhos de classe são autarquias que desenvolvem uma atividade técnica (fiscalização, registro e disciplina dos profissionais), atribuida por lei ${ }^{(5,10)}$.

O principal papel do Conselho de Classe da Enfermagem é disciplinar e fiscalizar o Exercício Profissional da Enfermagem, com o intuito de elevar a qualidade da assistência à saúde da população e, através da promoção do aprimoramento das ações de Enfermagem, defender o livre exercício da profissão de Enfermagem, observando os preceitos legais da profissão, publicando atos normativos visando o cumprimento da legislação pertinente a Enfermagem, além de atuar como órgão consultivo em problemas relacionados ao exercício profissional. Também cabe ao conselho realizar reuniões com os profissionais de enfermagem tendo como objetivo discutir aspectos relacionados ao exercício profissional e emissão de pareceres em processos inerentes ao exercício profissional de enfermagem ${ }^{(5)}$

No tocante à competência do conselho de classe, fica evidenciado que alguns profissionais não possuem ainda esclarecidas as verdadeiras competências do conselho de classe, mesclando-as com as atribuições do sindicato da categoria profissional, tendo em vista que o sindicato luta pela valorização e a realização profissional, com disponibilidade de serviço jurídico, apoiando e promovendo eventos que contribuam para o crescimento profissional da categoria como congressos, jornadas de carga horária, salários, cursos de aperfeiçoamento, especializações e atividades de lazer para os profissionais.

Quanto às responsabilidades e deveres dos profissionais, competem estarem inscritos no Conselho de Classe. exercer suas atividades profissionais, conhecer as atividades desenvolvidas pelo Conselho, efetuar assiduamente o pagamento das anuidades, votar nas eleições promovidas pelo Conselho Federal de Enfermagem, manter atualizado endereço individual, solicitar transferência de titularidade quando mudar para outro estado, requerer cancelamento quando encerrar as atividades profissionais por qualquer motivo, atender a todas as convocações do Conselho e, comunicar ao Conselho os casos de infrações éticas.

O estudo limitou-se no tocante ao quantitativo de profissionais que fizeram parte da amostra, algo que deve ser 
enfatizado à comunidade de entendido de enfermagem visando o despertar à ciência e melhorias do cotidiano e legislar da profissão, tendo em vista a grande contribuição que a percepção da classe sobre o seu respectivo conselho tem. Tal fato torna-se evidente, porém não compromete a evidência e pertinência das informações descritas e trabalhadas no estudo frente ao crescimento do saber inerente ao conselho para os enfermeiros e técnicos representados.

\section{LIMITAÇÕES E CONTRIBUIÇÕES DO ESTUDO}

Constituiu-se numa limitação a amostra pequena e localizada em apenas uma instituição. Todavia seus resultados podem auxiliar a reflexão sobre a atuação das entidades de classe, contribuindo para uma melhor aproximação com os profissionais.

\section{CONSIDERAÇÕES FINAIS}

Compete aos conselhos profissionais atuarem no sentido de coibir as práticas danosas, causadas principalmente pelo profissional de enfermagem nos usuários/pacientes assistidos pelos mesmos, bem como a outros companheiros de trabalho e, até mesmo, gestores/administradores dos serviços aos quais pertencem. Esses prejuízos podem ocorrer devido à falta de atenção, de habilitação ou conhe- cimento técnico profissional e/ou desconhecimento da legislação que disciplina o exercício da enfermagem no Brasil.

Constatou-se que os profissionais de enfermagem ainda, prioritariamente, desconhecem o verdadeiro papel do seu conselho fiscalizador, atribuindo muitas vezes a ele as funções que deveriam ser exercidas pelos sindicatos, que têm o dever de lutar por melhorias nas condições de trabatho a que estão sujeitos. Logo, ao conselho profissional fica a responsabilidade de envidar esforços no sentido de aproximar os profissionais, através de campanhas educativas e de valorização profissional. Isso poderá ser proporcionado com a união do conselho aos sindicatos que representam as diversas categorias que compõem a enfermagem, assim como a Associação Brasileira de Enfermagem (ABEn), que tem como função principal realizar eventos culturais e defender também os interesses da enfermagem como um todo.

Toda a conduta ética profissional deve ser baseada nos dispositivos constantes do Código de Ética dos Profissionais de Enfermagem. Uma melhor e maior divulgação deste dispositivo ético fará com que as condutas profissionais sejam realizadas de forma consciente e menos danosas aos inúmeros usuários dos serviços de saúde. Cabe, primordialmente, ao conselho fiscalizador adotar tal medida.

\section{REFERÊNCIAS}

1. Geovanni, T. História da Enfermagem: versões e interpretações. Rio de Janeiro, 2. ed., Revinter: São Paulo, 2002.

2. Queiroz DL, Souza JC. Qualidade de vida e capacidade para o trabalho de profissionais de enfermagem. Rev Psic Inform [Internet]. 2015[cited Jun 01]; 1(2):103-116. Available from: http://pepsic.bvsalud. org/scielo.php?script=sci_arttext\&pid=S1415-88092.pdf

3. Gabriela SS, Maria ST, Giacomasso V. Arte e ação: iluminando novos caminhos para a Enfermagem. Hist enferm Rev eletronica[Internet]. 2017 [cited Jun 01]; 8(2):73-83. Available from: http://here abennacional.org.br/here/v8/n2/a02.pdf

4. Bener LR. O trabalho da enfermagem hospitalar: o cuidado de si e o cuidado do outro. Rev Bras Enferm [Internet]. 2015 [cited Jun 15]; 54(1):108-118. Available from: http://www.scielo.br/scielo. php?script=sci_arttextEpid=\$0034-71672001000100012

5. Conselho Regional de Enfermagem da Paraiba. Legislação Básica para o exercício da enfermagem. 5. ed., João Pessoa-PB, 2015.

6. Moreno AC, Ferraz RL, Rodrigues ST, Lopes SOA. Atribuições dos Profissionais de Enfermagem na Estratégia de Saúde da Família, uma Revisão das Normas e Práticas. Rev Bras Ciên e Saúde [Internet]. 2015 [cited Jun 17]; 19(3): 233-240. Available from: periodicos.ufpb.br/index. php/rbcs/article/download/23355/15075

7. Martins CP, Luzio CA. HumanizaSUS policy: anchoring a ship in
space.Rev Interface comunicação saúde educação [Internet]. 2017 [cited Jul 03]; 21(60):13-22. Available from: http://www.scielo.br/pdf/ icse/v2ln60/1807-5762-icse-1807-576220150614.pdf

8. Braga LM, Torres LM, Ferreira VMF. Condições de trabalho e fazer em enfermagem. Rev Enferm UFJF [Internet]. 2015 [cited Jun 05]; 1(1):55-63. Available from: http://www.ufjf.br/revistadeenfermagem/ files/2015/05/10-Revista-de-Enfermagem-C07.pdf

9. Dalri BMCR. Carga horária de trabalho dos enfermeiros e sua relação com as reaçōes fisiológicas do estresse. Rev. LatinoAm. Enferm [Internet]. 2015 [cited 2018 Abr 02]: 22(6):259-269. Available from: http://www.scielo.br/pdf/rlae/v22n6/pt_0104-1169rlae-22-06-00959.pdf

10. Costa OE, Germano MR, Medeiros MS. A fiscalização do exercício profissional no conselho federal de enfermagem. Rev Enferm Atenção Saúde [Internet]. 2015 [cited Jul 18]; 6(2):20-32. Available from: http:// www.reme.org.br/artigo/detalhes/919

11. Vidotti V, Ribeiro RP, Galdino MJQ, Martins JT. Burnout Syndrome and shift work among the nursing staff. Rev Lat Am Enfermagem [Internet]. 2018 [cited 2018 Ago 17]; 26:e3022. Available from: http:// www.scielo.br/pdf/rlae/v26/pt_0104-1169-rlae-26-e3022.pdf

Recebido: 16/08/2018

Aceito: 23/09/2019 